\title{
Source Term Analysis of Long-Life 620 MWt BWR During Loss of Coolant Accident (LOCA)
}

\author{
Hidayati Amar ${ }^{1)}$, Zaki Su'ud ${ }^{2)}$, Ari Darmawan Pasek ${ }^{3)}$ \\ 1) Nuclear Energy Regulatory Agency \\ ${ }^{2)}$ Nuclear and Biophysics Research Division, Bandung Institute of Technology \\ ${ }^{3)}$ Dept. of Mechanical Engineering, Bandung Institute of Technology \\ e-mail: h.amar@bapeten.go.id ; szaki@fi.itb.ac.id ; aripasek@yahoo.com
}

Received 14 October 2010, Revised 17 December 2010, Accepted 10 January 2011

\begin{abstract}
Source term analysis on a long-life 620 MWt BWR has been performed. The study includes fuel cell calculations, multi-groups diffusion equation calculation with 8 groups of energy, source term calculation and dose calculation. The scope of the source term analysis includes fission product inventories calculation in core, their activity and their toxicity during the Loss of Coolant Accident (LOCA). The calculation based on the assumption that the reactor

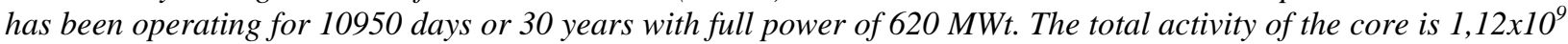
$\mathrm{Ci}$, and the higher inventory of the core is dominated by the trans-uranium elements. The release of fission product activity to the atmosphere is $1,11 \times 10^{7} \mathrm{Ci}$. And the toxicity analysis shows that noble gas has the higher toxicity degree. Whole body dose calculation result in exclusion zone is $7.17 \times 10^{-04} \mathrm{rem}$ and the thyroid dose calculation result in this zone is $7.21 \times 10^{-02}$ rem. And for the whole body dose calculation result in low population zone is $2.69 \times 10^{-05}$ rem and the thyroid dose calculation result in this zone resulted $1.80 \times 10^{-03}$ rem.
\end{abstract}

Keywords: Long-life BWR, LOCA, Source term, Activity, toxicity, Whole body dose, Thyroid dose, Exclusion and low population zone

\section{Introduction}

The increase of human population in the world especially in Indonesia causes the increase of demand. Nuclear energy could become one of the promising alternative energy sources for near future in Indonesia. The application of long life reactor in Indonesia is very suitable especially for remote area. Because of Indonesia geographical condition which is archipelago. Long life reactor can solve transportations problem of fuels during electric power generation. Long life reactors have high utilization so that economical value can be improved.

This research has been done to Long Life BWR $620 \mathrm{MWt}^{1)}$ with cylinder core and the operation period of this reactor is 30 years.

\section{Calculation Method}

The scope of this study includes fuel cell calculations, multigroup diffusion equation calculation with 8 group constants, source term calculation and dose calculation. And the source term analysis includes fission product inventories calculation in core, their activity and their toxicity during the Loss of Coolant Accident (LOCA).

For fuel cell calculation we use SRAC (Standard Reactor Analysis Code) code system. The Fuel geometry for the present study is described in Figure 1. Here we use hexagonal cell form to obtain low moderation environment.

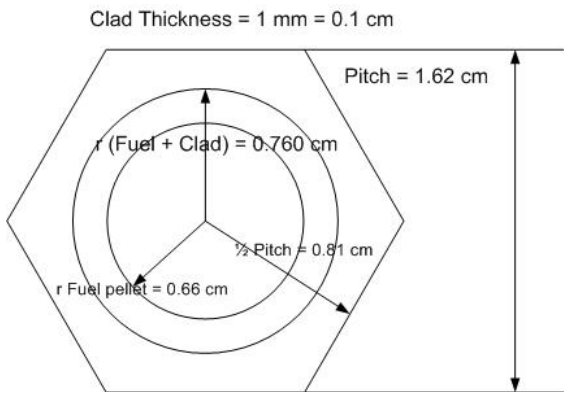

Figure 1. Cell Structure Geometry ${ }^{1)}$

And detail of cell configuration is listed in Table 1.

Table 1. Fuel element specifications ${ }^{1)}$

\begin{tabular}{|l|l|}
\hline Percentage fuel pellet & $60 \%$ \\
\hline Percentage Moderator (Air) & $20 \%$ \\
\hline Percentage Cladding (Zircaloy) & $20 \%$ \\
\hline Percentage Void axial & $0-40 \%$ \\
\hline Fuel element compositions & $(\mathrm{Th}-\mathrm{U}-\mathrm{Pa}) \mathrm{N}$ \\
\hline${ }^{233}$ U Enrichment Range & $8-11 \%$ \\
\hline Composition Range of ${ }^{231} \mathrm{~Pa}$ & $6-11 \%$ \\
\hline Pitch & $1.62 \mathrm{~cm}$ \\
\hline
\end{tabular}

The Cylindical core was divided into 3 radial region and 6 axial region. The first radial region was inner fuel with $8 \%$ of U-233 enrichment, and the second radial region was $11 \%$ of U-233 enrichment, and the last region was reflector. We used water as the reflector. Upper and bottom of the axial region were reflector, and four others axial region were $0 \%$ void, 
$10 \%$ void, $25 \%$ void and $40 \%$ void. The detail of core compotition is described in Figure 2.

\begin{tabular}{|c|c|c|c|}
\hline reflector & reflector & reflector & $32,4 \mathrm{~cm}$ \\
\hline $8 \%$ U-233 & $11 \% \mathrm{U}-233$ & & \\
\hline Enrichment & Enrichment & & \\
\hline $40 \%$ Void & $40 \%$ Void & reflector & $63,18 \mathrm{~cm}$ \\
\hline $8 \%$ U-233 & $11 \% \mathrm{U}-233$ & & \\
\hline Enrichment & Enrichment & & \\
\hline $25 \%$ Void & $25 \%$ Void & reflector & $63,18 \mathrm{~cm}$ \\
\hline $8 \%$ U-233 & $11 \% \mathrm{U}-233$ & & \\
\hline Enrichment & Enrichment & & \\
\hline $10 \%$ Void & $10 \%$ Void & reflector & $63,18 \mathrm{~cm}$ \\
\hline $8 \%$ U-233 & $11 \% \mathrm{U}-233$ & & \\
\hline Enrichment & Enrichment & & \\
\hline $0 \%$ Void & $0 \%$ Void & reflector & $63,18 \mathrm{~cm}$ \\
\hline reflector & reflector & reflector & $32,4 \mathrm{~cm}$ \\
\hline 74,5 & 74,52 & & \\
\hline
\end{tabular}

Figure 2. Core Material Compotition

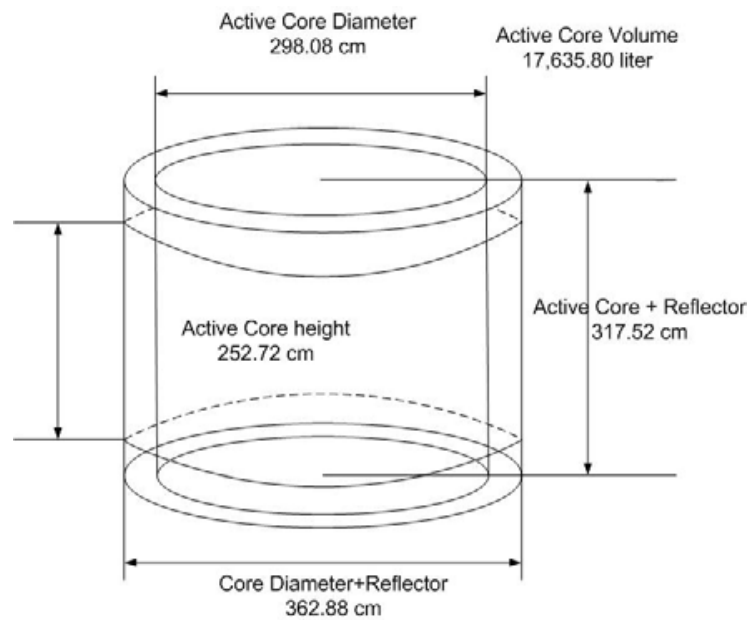

Figure 3. Form and dimensions of the first core ${ }^{1)}$

To calculate the neutron flux distribution we use the multigroup equation ${ }^{2-3)}$ which written below.

$$
\begin{aligned}
& \frac{1}{v_{g}} \frac{\partial \phi_{g}(\bar{r}, t)}{\partial t}-\bar{\nabla} \cdot D_{g}(\bar{r}) \bar{\nabla} \phi_{g}(\bar{r}, t)+\sum_{t g}(\bar{r}) \phi_{g}(\bar{r}, t)= \\
& \sum_{g^{\prime}=1}^{G} \sum_{s g^{\prime} g}(\bar{r}) \phi_{g^{\prime}}(\bar{r}, t)+\frac{\chi_{g}}{k_{\text {eff }}} \sum_{g^{\prime}=1}^{G} v_{g^{\prime}} \sum_{f g^{\prime}}(\bar{r}) \phi_{g^{\prime}}(\bar{r}, t)
\end{aligned}
$$

For the source term analysis, we assume that the accident was occurred because of the pipe breaking and the source term might release to the environment. There is no damage in containment but the safety system, such as ECCS, cavity and ventilating filter, works specifics to the radionuclide types. Noble gas was assumed that $100 \%$ released to the environment, $50 \%$ for the halogens released to the environment and $1 \%$ of the rest radionuclide released to environment. Table 2 shows the radionuclide groups.
Table 2. Radionuclide Groups ${ }^{4)}$

\begin{tabular}{|l|l|}
\hline \multicolumn{1}{|c|}{ Group } & \multicolumn{1}{c|}{ Elements } \\
\hline Noble Gases & $\mathrm{Xe}, \mathrm{Kr}$ \\
\hline Halogens & $\mathrm{I}, \mathrm{Br}$ \\
\hline Alkali Metals & $\mathrm{Cs}, \mathrm{Rb}$ \\
\hline Tellurium Group & $\mathrm{Te}, \mathrm{Sb}, \mathrm{Se}, \mathrm{Ba}, \mathrm{Sr}$ \\
\hline Noble Metals & $\mathrm{Ru}, \mathrm{Rh}, \mathrm{Pd}, \mathrm{Mo}, \mathrm{Tc}, \mathrm{Co}$ \\
\hline Lanthanides & $\begin{array}{l}\mathrm{La}, \mathrm{Zr}, \mathrm{Nd}, \mathrm{Eu}, \mathrm{Nb}, \mathrm{Pm}, \mathrm{Pr} \\
\mathrm{Sm}, \mathrm{Y}, \mathrm{Cm}, \mathrm{Am}\end{array}$ \\
\hline Cerium & $\mathrm{Ce}, \mathrm{Pu}, \mathrm{Np}$ \\
\hline
\end{tabular}

The activity inside the containment after the accident can be written as:

$$
c_{0}=8.46 \times 10^{5} F_{p} F_{b} P \gamma_{i}\left(1-e^{-\lambda_{i} t}\right) c_{i}
$$

The degree of toxic in the human body due to the amount of radioactive energy called toxicity. It is weighting by dose constrain which can be written as:

\section{Toxicity=Activity/Dose Limit}

The value of dose limit for each radionuclide is refers to annual limit intake for inhalation. The data is collected from 10 CFR 20 US-NRC Appendix B ${ }^{5)}$

The whole body and thyroid dose from gamma rays using the following equation ${ }^{3)}$

for whole body

$$
H=\frac{0.262 \bar{E}_{y} \lambda_{l}}{\pi \bar{v} \sigma_{y} \sigma_{z} \lambda_{c}}\left(1-e^{-\lambda_{c} t_{0}}\right) r e m
$$

$$
H=\frac{592 b \xi q \bar{E}_{y} \lambda_{l} C_{0}}{\pi \bar{v} \sigma_{y} \sigma_{z} M \lambda_{c} \lambda_{e}}\left(1-e^{-\lambda_{c} t_{0}}\right) r e m
$$

for thyroid.

The parametric used in this study are: the breathing rate $\mathrm{R}$ is $0.000347 \mathrm{~m} / \mathrm{s}, \sigma_{y}=30$ meters, $\sigma_{z}=$ 11 meters (in exclusion area zone) and $\mathrm{R}=0.000231$ $\mathrm{m} / \mathrm{s}, \quad \sigma_{y}=220$ meters, $\sigma_{z}=40$ meters (in low population zone).

\section{Calculation Result and Discussion}

\subsection{Neutron flux distribution}

Figure 4 and 5 describes two dimension neutron flux distribution, radial and axial region. Neutron flux decrease in the higher region enrichment because the fissile material was absorbs this neutron to fission. The flux neutron increases in the reflector region because this region contains material that reflects the neutron. 


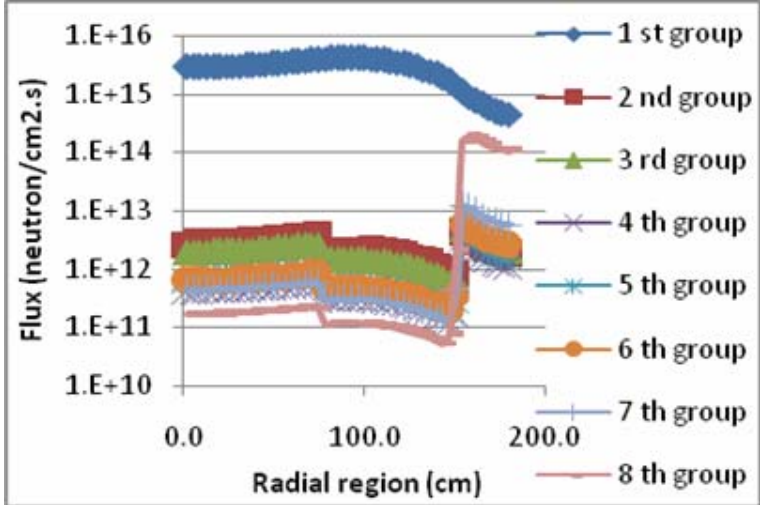

Figure 4. neutron flux distribution of each group in radial region

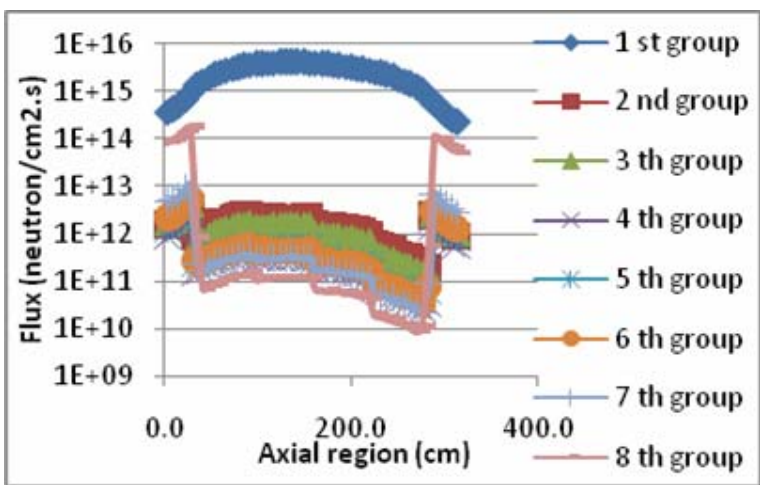

Figure 5. Neutron flux distribution of each group in axial region

\subsection{Source term analysis}

To analyze the source term in reactor core, we need to calculate the inventory and the activity of each radionuclide. To calculate the transuranium elements inventory we use SRAC output data, and for the fission product we use data from JNDC (Japan Nuclear Data Center). Figure 6 to 9 are the results of the source term calculation. Figure 6 describes the top 30 radionuclide inventory inside the core in 10950 days or 30 years, most of it is transuranium elements and the rest are fission product elements.

The total activity in the core is $1.12 \mathrm{E}+09 \mathrm{Ci}$. The top 30 activity is dominated by fission product elements. And the highest activity is I-134 with $1.759 \mathrm{E}+07 \mathrm{Ci}$.

The activity inside the containment in 2 hours after the accident describes in figure 8 . The figure shows the top 30 radionuclide and the noble gas has the highest activity inside the containment.

Krypton- 88 was the radionuclide with the biggest toxicity degree.

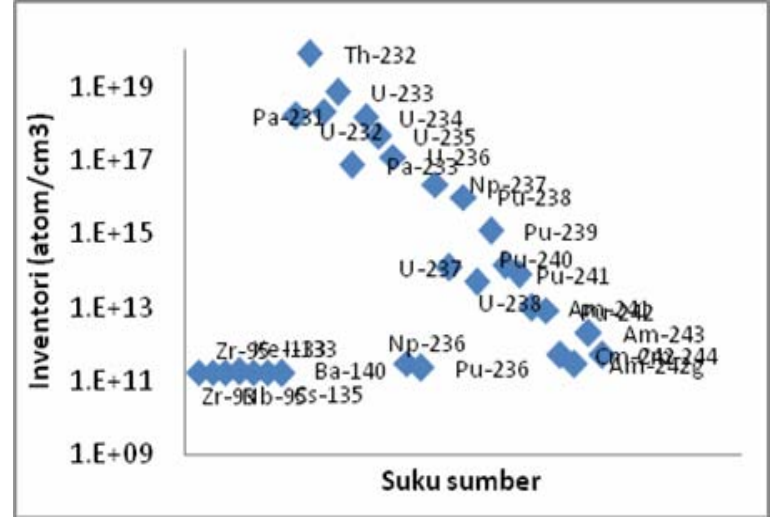

Figure 6. Radionuclide inventory inside the reactor core (Top 30)

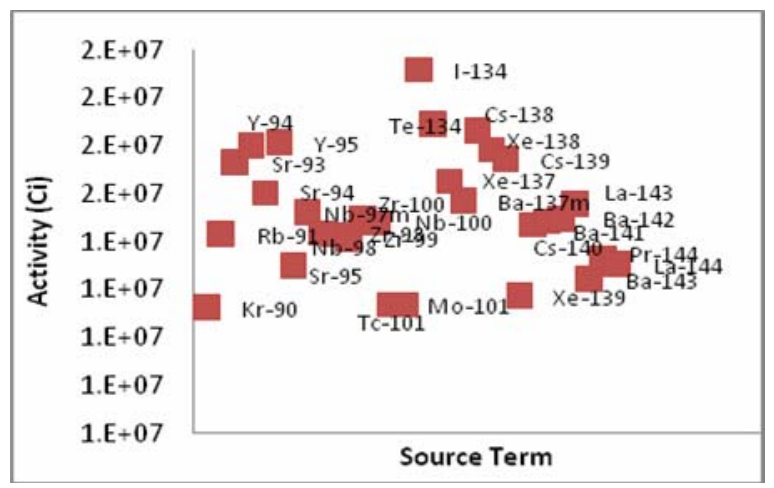

Figure 7. Radionuclide activity inside the reactor core (Top 30)

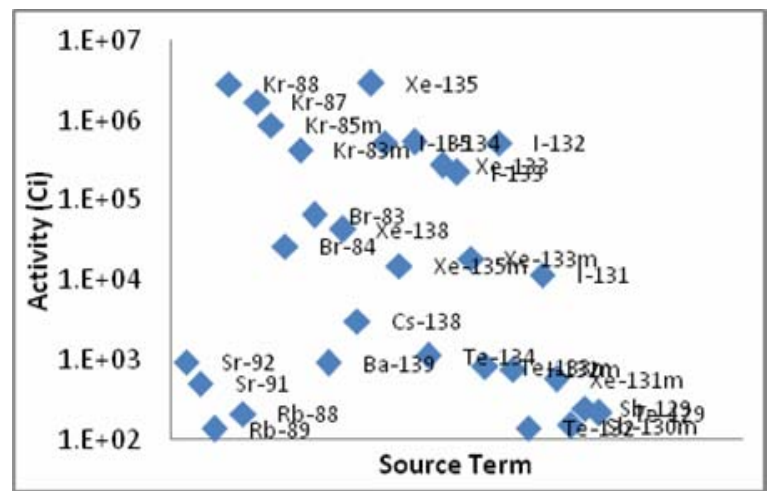

Figure 8 . Radionuclide activity inside the containment (Top 30)

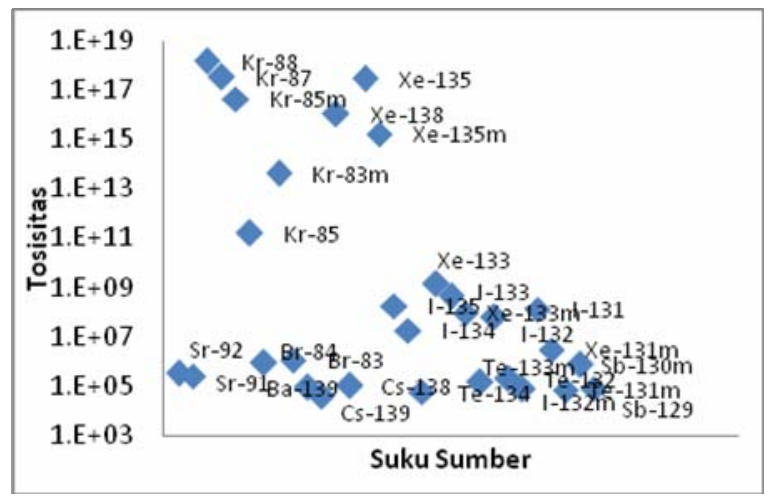

Figure 9. Source term toxicity degree (Top 30) 
The clearance time of each radionuclide has been calculated. The result shows that Plutonium 239, Neptunium 236 and Neptunium 237 have long clearance time.

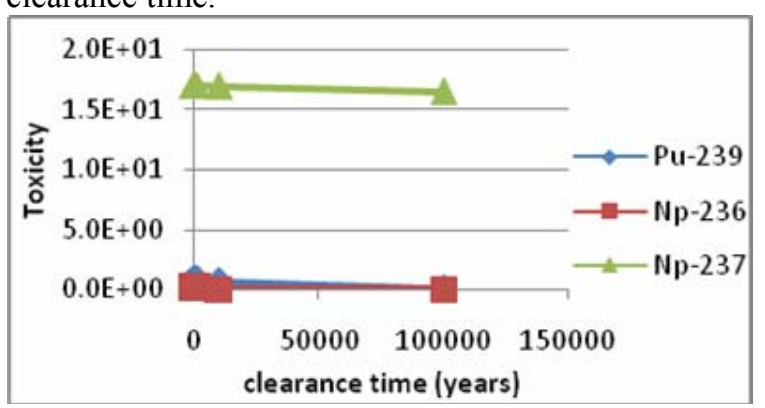

Figure 10. Clearance time for $\mathrm{Pu}-239, \mathrm{~Np}-236$ and $\mathrm{Np}-237$

The dose calculation results describes in Table 3.

Table 3. the total dose exposure

\begin{tabular}{|c|c|c|c|}
\hline Zone & Body organ & Dose (rem) & $\begin{array}{c}\text { Dose Limit } \\
(\mathbf{r e m})\end{array}$ \\
\hline \multirow{2}{*}{$\begin{array}{c}\text { Exclusion } \\
\text { Area Zone }\end{array}$} & Thyroid & $7.21 \mathrm{E}-02$ & $\leq 1$ \\
\cline { 2 - 4 } & Whole body & $7.17 \mathrm{E}-04$ & 1.25 \\
\hline $\begin{array}{c}\text { Low } \\
\text { Population } \\
\text { Zone }\end{array}$ & Thyroid & $1.80 \mathrm{E}-03$ & $<1$ \\
\cline { 2 - 4 } & Whole body & $2.63 \mathrm{E}-04$ & $<1$ \\
\hline
\end{tabular}

\section{Conclusion}

From above discussion we can conclude that the calculation based on the assumption that the reactor has been operating for 10950 days or 30 years with full power of $620 \mathrm{MWt}$. The total activity of the core is $1,12 \times 10^{9} \mathrm{Ci}$, and the higher inventory of the core is dominated by the trans-uranium element. The release of fission product activity to the atmosphere is
$1,11 \times 10^{7} \mathrm{Ci}$. And the toxicity analysis shows that noble gas has higher toxicity degree than the other elements. Whole body dose calculation result in exclusion zone is $7.17 \times 10^{-04}$ rem and the thyroid dose calculation result in this zone is $7.21 \times 10^{-02} \mathrm{rem}$. And for the whole body dose calculation result in low population zone is $2.69 \times 10^{-05}$ rem and the thyroid dose calculation result in this zone resulted $1.80 \times 10^{-03} \mathrm{rem}$.

\section{References}

1. E.S. Riyana, Z. Su'ud, Preliminary Design Study of Thorium (Th-232) and Protactinium (Pa-231) Based Fuel for Tight Lattice Long Life BWR, Proc. of GLOBAL 2005 Tsukuba, Japan, Oct 913, 2005, Paper No. 509

2. James. J. Duderstadt, Nuclear Reactor Analysis, John Wiley \& Sons, New York, 1976.

3. John R. Lamarsh, Introduction to Nuclear Engineering, $2^{\text {nd }}$ Edition, Addison Publ. Co., 1983.

4. United State Nuclear Regulatory Commission, Regulatory Guide 1.183, Alternative Radiological Source Terms for Evaluating Design Basis Accidents at Nuclear Power Reactors, 2000.

5. United State Nuclear Regulatory Commission : 10 CFR part 20 Appendix B Annual Limits on Intake (ALIs) and Derived Air Concentrations (DACs) or Radionuclides for Occupational Exposure; Effluent Concentrations; Concentrations for Release to Sewerage.

6. United State Nuclear Regulatory Comission: Regulatory Guide 1.3 Assumptions Used for Evaluating the Potential Radiological Consequences of Coolant Accident for Boiling Water Reactors, 1974. 